\title{
Eskişehir ilindeki çocuklarda diş çürüğü ve florozis görülme sıklığının değerlendirilmesi ${ }^{*}$
}

\author{
Elmas Egemen(0000-0003-3204-4609) ${ }^{\alpha}$, Nuray Tüloğlu(0000-0001-6410-9126) ${ }^{\beta}$
}

Selcuk Dent J, 2019; 6: 297-308 (Doi: 10.15311/selcukdentj.481321)

Başvuru Tarihi: 10 Kasım 2018 Yayına Kabul Tarihi: 12 Şubat 2019

\begin{abstract}
öz
Eskişehir ilindeki çocuklarda diş çürüğü ve florozis görülme sıklığının değerlendirilmesi
\end{abstract}

Amaç: Bu araştırmada, Eskişehir ilindeki çocuklarda diş çürüğü ve dental florozis görülme sıklı̆ının değerlendirilmesi amaçlandı. Ayrıca dental florozisin etiyolojik faktörleri ve dental florozis görülme sıklığının diş çürüğü ile ilişkisi de değerlendirildi.

Gereç ve Yöntemler: Araştırmaya, Eskişehir ilindeki 8-12 yaş arasındaki toplam 4936 çocuk dahil edildi. Diş çürüğünün değerlendirilmesinde dft/DMFT indeksi, dental florozisin değerlendirilmesinde ise Thylstrup-Fejerskov İndeksi kullanıldı. Ayrıca çocukların ebeveynleri tarafından dental florozise neden olabileceği öne sürülen etiyolojik faktörleri içeren anamnez formu dolduruldu. Kullanılan içme sularının florür konsantrasyonları iyon kromatografi cihazı kullanılarak tespit edildi. Elde edilen verilerin istatistiksel değerlendirmesinde Mann Whitney-U Testi, Kruskal Wallis Testi ve Spearman Korelasyon testi kullanıldı.

Bulgular: Araştırmaya katılan çocukların ortalama DMFT değeri 2.18 \pm 2.00 , dental florozis görülme sıklığı ise \% 1.9 olarak belirlendi. Dental florozis görülme sıklığı açısındanile ilçeler arasında anlamlı bir fark olduğu $(p<0.001)$ ve en yüksek dental florozis görülme oranının sudaki florür konsantrasyonunun optimum dozun üzerinde olan Çifteler ilçesinde (\% 15.2) olduğu saptandı. Dental florozis görülmesi ile diş çürüğü arasında negatif korelasyon olduğu tespit edildi $(p<0.01)$. Ayrıca anne/babanın eğitim düzeyi, doğumdan itibaren aynı bölgede yaşaması, anne sütü ile beslenme süresi, içme suyunun tipi, okulda kullanılan suyun tipi, macun tipi ile çocukta dental florozis görülme sıklığı arasında anlamlı bir ilişki olduğu belirlendi $(p<0.05)$.

Sonuç: : Sonuç olarak, dental florozis görülmesinde içme suyundaki florür konsantrasyonunun yanı sıra anne sütü ile beslenme süresi ve kullanılan macun tipi gibi diğer faktörlerin de rol oynadığı ve dental florozis önlenmesinde tüm etiyolojik faktörlerin göz önünde bulundurulması gerektiğini düşünmekteyiz.

\section{ANAHTAR KELIMELER}

Çocuk, dental florozis, diş çürüğü, Eskişehir

Çocuk diş hekimliğinin birincil amacı, diş çürüğüne bağı ortaya çıkan problemleri çözmekten çok problemlerin oluşmasını engelleyecek önlemleri almaktır. ${ }^{1}$ Diş çürüklerinin önlenmesinde ya da

\section{ABSTRACT}

Evaluation of dental caries and fluorosis prevalence of children in Eskisehir

Background: This study aimed to evaluate the prevalence of the dental caries and dental fluorosis in children living in Eskişehir. The etiological factors of the dental fluorosis and the correlation of the prevalence of dental fluorosis between dental caries were also determined.

Methods: 4936 children between 8-12 years-old in Eskişehir were included. dft/DMFT and Thylstrup-Fejerskov index were used for the evaluation of the dental caries and fluorosis. Furthermore, the parents of the children were asked to fulfill an anamnesis form including the etiological factors, which were considered as the possible cause of the dental fluorosis. The fluoride concentrations of the drinking water were determined by the ion-chromatography. Statistical analysis was performed using Mann Whitney-U, Kruskal Wallis and the Spearman's Correlation Tests.

Results: The mean DMFT score was $2.18 \pm 2.00$, dental fluorosis prevalence was $1.9 \%$ in the participating children. There was a significant difference between the towns regarding the prevalence of the dental fluorosis $(p<0.001)$. The highest prevalence of dental fluorosis was determined in Çifteler $(15.2 \%)$, where the flour concentration in the water was above the optimal dose. A negative correlation was determined between the prevalence of the dental fluorosis and caries $(p<0.01)$. Furthermore, a significant correlation was also determined between the dental fluorosis and the parental education level, living in the same region since birth, duration of the feeding with the mother's milk, the type of the drinking water, the type of the water used in the school and the type of the toothpaste $(p<0.05)$.

Conclusion: We conclude that along with the fluoride concentration in the drinking water also other factors such as the duration of the feeding with the mother's milk and the type of the used toothpaste are playing an important role in the prevalence of the dental fluorosis and all etiological factors should be taken into the consideration for the prevention it.

\section{KEYWORDS}

Child dental fluorosis, dental caries, Eskişehir

başlangıç halindeki çürük lezyonlarının durdurulmasında en yaygın olarak kullanılan ve en etkili yöntemlerden biri florür uygulamalarıdır. ${ }^{2}$ Son yıllarda, toplumun diş çürüğünden korunma yöntemleri

\footnotetext{
${ }^{*}$ Bu araşttrma 12-14 Ekim 2018 tarihinde 25.Türk Pedodonti Derneği Kongresinde Poster olarak sunulmuştur. "Nuray Tuloglu, Elmas Egemen. Prevalence of the dental fluorosis in Eskisehir, Turkey. International Association of Paediatric Dentistry Regional Meeting \& 25th Congress of Turkish Society of Paediatric Dentistry Istanbul, TURKEY, October 12-14, 2018.

${ }^{\alpha}$ Serbest Çocuk Diş Hekimi, Bursa

${ }^{\beta}$ Eskişehir Osmangazi Üniversitesi Diş Hekimliği Fakültesi Çocuk Diş Hekimliği Anabilim Dalı, Eskişehir 
hakkında bilinçlenmesi ve florür kullanımının yaygınlaşmasına bağlı, gelişmiş ülkelerde diş çürüğü prevalansında ve insidansında düşüş gözlendiği, buna karşın dental florozis prevalansında ise artış görüldüğü bildirilmektedir. ${ }^{3-8}$

Dental florozis, sağlıklı bireyler için önerilen optimum miktarın üzerindeki florürün dişlerin gelişim dönemi sırasında sistemik olarak alınımı ile meydana gelen, normal mine yapısına göre poröziteler ile karakterize olan minenin yapısal bozukluğudur.6,9-12 Dental florozisin şiddeti, maruz kalınan florür miktarına, süreye, dişlerin ve kemiğin gelişim dönemine, bireyin kilosuna ve beslenme alışkanlıklarına bağlı olup klinik olarak diş yüzeyleri boyunca gözlenen ince beyaz çizgilerden, kahverengimsi renklenmelere ve mine yüzeyinde oluşan çukurcuklara kadar farklı şekillerde görünebilmektedir.6,13,14 Doğal içme suyu ve kaynaklarındaki florür konsantrasyonunun yüksek olması, içme sularının yanı sıra florlu bebek mamaları gibi yiyecek ve içeceklerin, florlu diş macunlarının ve florlu tabletlerin kullanımının ve florür uygulama yöntemlerinin yaygınlaşması dental florozis için risk oluşturmaktadır. ${ }^{15-23}$

Ülkemizde florür ile ilgili epidemiyolojik araştırmalar oldukça sınırıdır. ${ }^{24-32}$ Ayrıca çocuklarda diş çürüğü ve dental florozis arasındaki ilişkiyi değerlendiren çalışmalar incelendiğinde, farklı ülkelerde yapılan çalışmalar olmasına rağmen $n^{4,7,8,19,33-42}$ ülkemizde sınırlı sayıda çalışma bulunduğu görülmektedir. ${ }^{32,43}$ Bu nedenle, bu araştırmada, Eskişehir ilindeki çocuklarda dental florozis görülme sıklığının ve etiyolojik faktörlerinin değerlendirilmesi, dental florozis görülme sıklığının diş çürüğü ile ilişkisinin belirlenmesi amaçlandı.

\section{GEREÇ VE YÖNTEM}

Araştırmanın etik kurul onayı Eskişehir Osmangazi Üniversitesi Girişimsel Olmayan Klinik Araştırmalar Etik Kurulu'ndan (Karar Tarihi: 30.05.2016; Karar No: 11) ve araştırmanın planlanan bölgedeki ilkokul ve ortaokullarda yürütülebilmesi için gerekli resmi izinler Eskişehir Valiliğinden ve Eskişehir î̀ Milli Eğitim Müdürlüğü'nden alındı.

Araştırmaya dahil edilen öğrencilerle ebeveynlerine gönderilen aydınlatımış onam formları hasta ve/veya ebeveynleri tarafından onaylandı.

\section{Çalışma grubunun oluşturulması}

Eskişehir ill Milli Eğitim Müdürlüğü'nden, Eskişehir il merkezinde ve ilçelerinde bulunan tüm ilkokul ve ortaokulların isimleri ve bu okulların öğrenci mevcutlarının ne kadar olduğu öğrenildi. Eskişehir 2007 yılındaki nüfus sayım bilgilerine göre nüfusa orantılı küme örneklem yöntemiyle örneklem sayısı en az 4000 olarak hesaplandı. Toplumun genelini yansıtması açısından randomize olarak ve her ilçeden en az bir okulu kapsayacak şekilde 32 adet ilkokul ve ortaokuldaki öğrencilerin muayene edilmesi planlandı.

Araştırmaya 8-12 yaş arasındaki Eskişehir il sınırlarındaki ilkokul ve ortaokul öğrencilerinden aydınlatılmış onam formu alınmış olanlar dâhil edildi. Ailesinde kalıtsal hastalık hikayesi bulunan, ortodontik tedavi gören, ön dişlerinde restorasyon bulunan, travmatik diş yaralanması olan, florozis dışında dental renklenme/hipoplazisi olan ve yazilı onamları alınamayan öğrenciler araştırmaya dahil edilmedi.

\section{Ağız içi değerlendirme ve anamnez formlarının uygulanması}

Ekim 2016-Kasım 2016 tarihleri arasında, çalışma grubundaki tüm çocukların ağız içi muayenesi, sınıflarında pencere kenarında sandalyeye oturtularak ve gün ışığında ayna-sond kullanılarak yapıldı. Tüm çocukların ağız içi muayenesi tek bir diş hekimi (E.E.) tarafından gerçekleştirilerek hasta bilgi formuna kaydedildi. Muayene öncesinde dişlerin yüzeyindeki plak pamuk tamponlarla temizlendikten sonra diş yüzeyleri kurutularak değerlendirildi.

Diş çürüğünün değerlendirilmesinde, süt ve daimi dişlerde $\mathrm{dft} / \mathrm{DMFT}$ indeksi kullanıldı. Örneklem grubunun dft/DMFT değeri çürük (d-D), çürük nedeniyle çekilmiş $(M)$ ve çürük nedeniyle dolgu yapılmış (f-F) dişlerin toplamının toplam muayene olan kişi sayısına bölünmesiyle elde edildi. Abrazyonlu ve florozisli dişler çürük açısından sağlam kabul edildi. ${ }^{44}$

Dental florozis tanısı konan çocuklarda florozisin şiddetini belirlemek için Thylstrup-Fejerskov İndeksi $(\mathrm{TFI})^{45}$ kullanıldı. Derecelendirmede TFI değeri en yüksek olan diş dikkate alınarak kaydedildi.

Literatürlerde dental florozise neden olabileceği öne sürülen etiyolojik faktörleri içeren anamnez formu hazırlandı. Çocuklar tarafından ebeveynlere gönderilen anamnez formları bir hafta sonra toplandı. Eksik anamnez formlarının toplanması için okullara tekrar gidildi.

\section{Su örneklerinin toplanması ve flor analizi}

Anamnez formlarından, araştırmaya katılan öğrencilerin yeme ve içme amaçlı tükettiği su çeşidi (şebeke/artezyen kuyu/hazır şişelenmiş su) öğrenildi ve bu suların florür iyon analizleri yapıldı. Kullanıldığı öğrenilen tüm sulardanKullanılan sular pet şişelere doldurularak birer adet numuneler alındı. Sulardaki florür iyonlarının analizinde iyon kromatografi cihazı (ICS-3000 Ion chromatography system, Thermo Dionex Co., California, USA) kullanıldı. Alınan numunelerin analizi Anadolu Üniversitesi Bitki, Illaç ve Bilimsel Araştırmalar Merkezi'nde yapıldı. 


\section{İstatistiksel değerlendirme}

Araştırmada elde edilen verilerin istatistiksel analizleri "Statistical Package for the Social Sciences" yazılımı (SPSS 21 for Windows, SPSS Inc., Chicago, Illinois, USA) kullanılarak gerçekleştirildi.

Nicel veriler medyan (Q1-Q2), nitel veriler frekans ve yüzde olarak gösterildi. Verilerin normal dağılıma uygunluğu Shapiro Wilk Testiyle araştııılı. Veriler normal dağılmadığı için bağımsı iki grubun karşılaştırılması Mann Whitney-U Testi ile, bağımsız üç ve daha fazla grubun karşılaştırılması Kruskal Wallis Testi ile yapıldı. Nicel değişkenler arasındaki ilişki Spearman Korelasyon analiziyle incelendi.

Analizlerde istatistiksel anlamlılık düzeyi $p<0.05$ olarak kabul edildi.

\section{BULGULAR}

\section{Araştırmaya katılan çocukların demografik bulguları}

Araştırmaya 2432'sı kı (\% 49.27), 2504'sı erkek (\% 50.73) olmak üzere 812 yaş aralığındaki (ortalama $9.37 \pm 1.03$ yaş) toplam 4936 çocuk dahil edildi. Araştırmaya dahil edilen çocuklar, Eskişehir ilinin 2 merkez ve 12 çevre ilçesindeki toplam 32 adet ilkokul ve ortaokuldan seçildi (Tablo 1).

\section{Araştırmaya katılan çocukların dft/DMFT değerleri}

Araştırmaya katılan tüm çocukların ortalama DMFT değeri $2.18 \pm 2.00$ olarak saptandı. DMFT değerlerinde ilçeler arasında anlamlı bir fark olduğu gözlendi $(p<0.001)$ (Tablo 2). Kız ve erkek çocukların DMFT ortalamasının ise benzer olduğu gözlendi (kızlarda $2.15 \pm 1.97$, erkeklerde $2.20 \pm 2.03$ ).
Tablo 1.

Araştırmaya katılan çocukların ilçe, okul ve yaşa göre dağılımı

\begin{tabular}{|c|c|c|c|c|c|c|c|}
\hline \multirow{2}{*}{ İlçe } & \multirow[b]{2}{*}{ Okul } & \multicolumn{6}{|c|}{ Yaş (n) } \\
\hline & & 8 & 9 & 10 & 11 & 12 & $\begin{array}{c}\text { Topla } \\
\text { m }\end{array}$ \\
\hline \multirow[t]{2}{*}{ Alpu } & Atatürk İlkokulu & 49 & 21 & 0 & 0 & 0 & 70 \\
\hline & Bozan Veli Topçu Ortaokulu & 0 & 8 & 25 & 30 & 31 & 94 \\
\hline \multirow{2}{*}{ Beylikova } & Mehmet Avdan İlkokulu & 34 & 7 & 0 & 0 & 0 & 41 \\
\hline & Mehmet Avdan Ortaokulu & 0 & 12 & 23 & 29 & 24 & 88 \\
\hline \multirow{4}{*}{ Çifteler } & Gazi İlkokulu & 54 & 18 & 0 & 0 & 0 & 72 \\
\hline & Fatih İlkokulu & 50 & 28 & 2 & 0 & 0 & 80 \\
\hline & Atatürk Ortaokulu & 1 & 0 & 21 & 164 & 9 & 195 \\
\hline & Yakup Kadri Karaosmanoğlu Ortaokulu & 1 & 6 & 36 & 108 & 3 & 154 \\
\hline \multirow{2}{*}{ Günyüzü } & Şehit Mücahit Top İlkokulu & 40 & 2 & 0 & 0 & 0 & 42 \\
\hline & Günyüzü Ortaokulu & 1 & 8 & 19 & 27 & 17 & 72 \\
\hline \multirow{2}{*}{ Han } & Şehit Osman Gazi Altınoluk Illkokulu & 18 & 8 & 0 & 0 & 0 & 26 \\
\hline & Şehit Osmangazi Altınoluk Ortaokulu & 0 & 0 & 15 & 10 & 13 & 38 \\
\hline \multirow{2}{*}{ İnönü } & Şehit Ali İhsan Aydın İlkokulu & 49 & 28 & 0 & 1 & 0 & 78 \\
\hline & Vehbi Koç Ortaokulu & 0 & 11 & 28 & 24 & 20 & 83 \\
\hline \multirow{2}{*}{ Mahmudiye } & Atatürk İlkokulu & 45 & 22 & 0 & 0 & 1 & 68 \\
\hline & Mahmudiye Ortaokulu & 1 & 24 & 62 & 56 & 53 & 196 \\
\hline \multirow{2}{*}{ Mihalgazi } & Mihalgazi ilkokulu & 21 & 13 & 0 & 0 & 0 & 34 \\
\hline & Mihalgazi Ortaokulu & 0 & 0 & 16 & 15 & 23 & 54 \\
\hline Mihalıççık & Hürriyet İlkokulu & 56 & 35 & 2 & 0 & 0 & 93 \\
\hline \multirow{3}{*}{ Odunpazarı } & Ahmet Sezer Ortaokulu & 2 & 46 & 136 & 318 & 11 & 513 \\
\hline & Milli Zafer İlkokulu & 414 & 256 & 4 & 0 & 0 & 674 \\
\hline & Meserret İnel İlkokulu & 398 & 282 & 6 & 0 & 0 & 686 \\
\hline \multirow{2}{*}{ Sarıcakaya } & Fatih İlkokulu & 42 & 25 & 0 & 0 & 0 & 67 \\
\hline & Sarıcakaya Ortaokulu & 0 & 5 & 13 & 26 & 20 & 64 \\
\hline \multirow{4}{*}{ Seyitgazi } & Kırka Atatürk Illkokulu & 38 & 37 & 0 & 0 & 0 & 75 \\
\hline & Kırka Mehmet Akif Ersoy Ortaokulu & 0 & 13 & 37 & 38 & 35 & 123 \\
\hline & Şehit Mustafa Akbaş İlkokulu & 45 & 24 & 1 & 0 & 0 & 70 \\
\hline & Şehit Kamil Üngör Ortaokulu & 36 & 17 & 1 & 0 & 0 & 54 \\
\hline \multirow{2}{*}{ Sivrihisar } & Hasan Karacalar İlkokulu & 45 & 28 & 2 & 0 & 0 & 75 \\
\hline & Hasan Karacalar Ortaokulu & 0 & 8 & 49 & 53 & 0 & 110 \\
\hline \multirow{2}{*}{ Tepebaşı } & Barbaros illkokulu & 281 & 190 & 2 & 1 & 0 & 474 \\
\hline & İki Eylül Ortaokulu & 4 & 48 & 151 & 167 & 3 & 373 \\
\hline Toplam & & 1725 & 1230 & 651 & 1067 & 263 & 4936 \\
\hline
\end{tabular}


Tablo 2.

\section{DMFT'nin ilçelere göre dağılımı}

\begin{tabular}{|lcc|}
\hline İlçe & $\begin{array}{c}\text { Muayene } \\
\text { edilen } \\
\text { Çocuk } \\
\text { sayısı (n) }\end{array}$ & $\begin{array}{c}\text { DMFT } \\
\text { (Ortalama } \pm \text { Standart } \\
\text { Sapma) }\end{array}$ \\
\hline Alpu & 164 & $3.01 \pm 2.06$ \\
\hline Beylikova & 129 & $2.65 \pm 2.09$ \\
\hline Çifteler & 501 & $2.04 \pm 2.14$ \\
\hline Günyüzü & 114 & $2.42 \pm 2.06$ \\
\hline Han & 64 & $1.89 \pm 1.53$ \\
\hline İnönü & 161 & $2.44 \pm 2.19$ \\
\hline Mahmudiye & 264 & $2.93 \pm 2.18$ \\
\hline Mihalgazi & 88 & $2.30 \pm 2.15$ \\
\hline Mihalıççık & 93 & $2.02 \pm 1.85$ \\
\hline Odunpazarı & 1873 & $1.76 \pm 1.71$ \\
\hline Sarıcakaya & 131 & $2.36 \pm 1.95$ \\
\hline Seyitgazi & 322 & $1.96 \pm 1.79$ \\
\hline Sivrihisar & 185 & $2.37 \pm 2.07$ \\
\hline Tepebaşı & 847 & $2.67 \pm 2.11$ \\
\hline Toplam & 4936 & $2.18 \pm 2.00$ \\
\hline
\end{tabular}

Araştırmaya katılan çocuklarda dental florozis görülme sıklığı ve şiddeti

Araştırmaya katılan 4936 çocuğun 93 tanesinde (58 kız, 35 erkek) dental florozis olduğu ve Eskişehir ilinde dental florozis görülme sıklığının \% 1.9 olduğu saptandı. Kızlarda dental florozis görülme sıklığının (\% 2.4) erkeklerden (\% 1.4) istatistiksel olarak daha fazla olduğu belirlendi $(p=0.11)$ (Tablo 3 ). Araştırmada, en sık TFI 1 ve en yüksek TFI 4 skoru gözlenirken, TFI 5-9 skorları hiç gözlenmedi.

Dental florozis görülme sıklığının ilçelere göre dağılımı Tablo 4'de gösterilmektedir. Beylikova, İnönü, Mihalgazi, Mihallıççık, Sarıcakaya, Sivrihisar ve Odunpazarı ilçelerinde dental florozis gözlenmezken, ilçeler arasında en yüksek dental florozis görülme oranının Çifteler ilçesinde (\% 15.2) olduğu saptandı. Dental florozis görülme sıklığı açısından ilçeler arasında anlamlı bir fark olduğu gözlendi $(p<0.001)$.
Tablo 3.

Dental florozis görülme sıklığının ve şiddetinin cinsiyete göre
dağılımı

\begin{tabular}{|c|c|c|c|c|c|c|c|}
\hline \multirow[b]{2}{*}{ Cinsiyet } & \multirow{2}{*}{$\begin{array}{c}\text { Muayene } \\
\text { edilen } \\
\text { çocuk } \\
\text { sayısı } \\
\text { n }\end{array}$} & \multicolumn{5}{|c|}{ TFI } & \multirow{2}{*}{$\begin{array}{c}\text { Dental } \\
\text { florozis } \\
\text { gözlenenler } \\
\text { n (\%) }\end{array}$} \\
\hline & & $\begin{array}{c}0 \\
\text { n (\%) }\end{array}$ & $\begin{array}{c}1 \\
\text { n (\%) }\end{array}$ & $\begin{array}{c}2 \\
\text { n (\%) }\end{array}$ & $\begin{array}{c}3 \\
\text { n (\%) }\end{array}$ & $\begin{array}{c}4 \\
\text { n (\%) }\end{array}$ & \\
\hline $\mathrm{K} \mathrm{Iz}$ & 2432 & $2374(97.6)$ & $26(1.1)$ & $21(0.9)$ & $8(0.3)$ & $3(0.1)$ & $58(2.4)$ \\
\hline Erkek & 2504 & 2469 (98.6) & $20(0.8)$ & $12(0.5)$ & $2(0.1)$ & $1(0)$ & $35(1.4)$ \\
\hline Toplam & 4936 & 4843 (98.1) & $46(0.9)$ & $33(0.7)$ & $10(0.2)$ & $4(0.1)$ & $93(1.9)$ \\
\hline
\end{tabular}

Tablo 4.

Dental florozis görülme sıklığının ilçelere göre dağılımı

\begin{tabular}{|lcc|}
\hline İlçe & $\begin{array}{c}\text { Muayene } \\
\text { edilen } \\
\text { çocuk } \\
\text { sayısı (n) }\end{array}$ & $\begin{array}{c}\text { Dental } \\
\mathbf{n}(\%)\end{array}$ \\
\hline Alpu & 164 & $3(1.8)$ \\
\hline Beylikova & 129 & $0(0)$ \\
\hline Çifteler & 501 & $76(15.2)$ \\
\hline Günyüzü & 114 & $2(1.8)$ \\
\hline Han & 64 & $2(3.1)$ \\
\hline Inönü & 161 & $0(0)$ \\
\hline Mahmudiye & 264 & $6(2.3)$ \\
\hline Mihalgazi & 88 & $0(0)$ \\
\hline Mihalıççık & 93 & $0(0)$ \\
\hline Odunpazarı & 1873 & $0(0)$ \\
\hline Sarıcakaya & 131 & $0(0)$ \\
\hline Seyitgazi & 322 & $2(0.6)$ \\
\hline Sivrihisar & 185 & $0(0)$ \\
\hline Tepebaşı & 847 & $2(0.2)$ \\
\hline Toplam & 4936 & $93(1.9)$ \\
\hline
\end{tabular}

Dental florozis gözlenen ve gözlenmeyen çocuklarda diş çürüğü görülme sıklığının benzer olduğu ve istatistiksel olarak anlamlı bir fark olmadığı tespit edildi ( $p>0.05)$ (Tablo 5). Dental florozis ile diş çürüğü görülme sıklığı arasındaki ilişkili değerlendirildiğinde ise negatif bir korelasyon olduğu saptandı $(p<0.001)$. 
Tablo 5.

\section{Dental florozis ile diş çürüğü arasındaki ilişki}

\begin{tabular}{|lcc|c|}
\hline & \multicolumn{3}{c|}{ Diş Çürüğü } \\
\cline { 3 - 4 } $\begin{array}{l}\text { Dental } \\
\text { Florozis }\end{array}$ & $\mathbf{n}$ & $\begin{array}{c}\text { Yok } \\
\mathbf{n}(\%)\end{array}$ & $\begin{array}{c}\text { Var } \\
\mathbf{n}(\%)\end{array}$ \\
\hline Yok & 4843 & $901(18.6)$ & $3492(81.4)$ \\
\hline Var & 93 & $34(36.6)$ & $59(63.4)$ \\
\hline Toplam & 4936 & $935(18.9)$ & $4001(81.1)$ \\
\hline
\end{tabular}

Dental florozis görülme sıklığı ile etiyolojik faktörler arasındaki ilişkinin değerlendirilmesi

Anne/babanın eğitim düzeyi (negatif), doğumdan itibaren aynı bölgede yaşaması, anne sütü ile beslenme süresi (negatif), içme suyunun tipi, okulda kullanılan suyun tipi, macun tipi ile çocukta dental florozis görülme sıklığı arasında istatistiksel olarak anlamlı bir ilişki saptanırken $(p<0.05)$, çocukta sistemik hastalık varlığı, hazır mama kullanımı, mamanın markası, diş fırçalamaya başlama yaşı, fırçalama sıklığı, fırçalama süresi, macun miktarı, ağız temizliğinde kullanılan ürünler, florür uygulaması yapılması ve sayısı ile dental florozis görülme sıklığı arasında anlamlı bir ilişki saptanmadı $(p>0.05)$.

\section{Sulardaki florür oranının değerlendirilmesi}

Araştırmaya katılan çocukların kullandığı 22 farklı su (şebeke, artezyen kuyu, şişelenmiş su) toplandı ve suların florür analizleri yapıldı (Tablo 6). Çifteler, Sarıcakaya ve Han ilçelerinde artezyen kuyu suyu ya da şişelenmiş su kullanıldığı, diğer tüm ilçelerde ise şebeke suyu ya da şişelenmiş su kullanıldığı tespit edildi. Yapılan analiz sonucu kullanılan şişelenmiş sularda (Damla, Erikli, Gecek, Kalabak, Kirazı, Saka, Nestle) ve İnönü, Mihalıççık ve Sarıcakaya ilçelerinin şebeke suyunda florür saptanmadı. Kullanılan artezyen kuyu sularının ortalama florür konsantrasyonu 0.976 ppm, şebeke sularının ise 0.161 ppm olduğu tespit edildi. Analiz sonucu en yüksek florür konsantrasyonuna Çifteler artezyen kuyu suyunun (1.441 ppm) sahip olduğu belirlendi. Kullanılan suyun tipi ile florür konsantrasyonu arasında istatistiksel olarak anlamlı bir fark olduğu saptandı $(p<0.001)$.

Öğrencilerin kullandıkları içme sularının florür konsantrasyonu ile dental florozis varlığı arasındaki ilişki değerlendiğinde, içme suyu florür konsantrasyonları ile dental florozis görülmesi arasında pozitif korelasyon olduğu saptandı $(p<0.05)$

Öğrencilerin kullandıkları içme sularının florür konsantrasyonu ile dental florozisin şiddeti karşılaştırıldığında ise içme suyu florür konsantrasyonunun arttıkça dental florozis şiddetinin de arttığı saptandı. İçme sularındaki florür konsantrasyonu ile florozis şiddeti arasında pozitif yönde istatiksel olarak zayıf bir ilişki olduğu tespit edildi $(p<0.001$; $r: 0.208)$.
Tablo 6.

İlçelere göre kullanılan sulardaki florür miktarı

\begin{tabular}{|c|c|c|}
\hline İlçe & Suyun Tipi & $\begin{array}{c}\text { Flor } \\
\text { Konsantrasyonu } \\
(p p m)\end{array}$ \\
\hline \multirow{2}{*}{ Alpu } & Şebeke & 0.332 \\
\hline & Şişelenmiş & 0 \\
\hline \multirow{2}{*}{ Beylikova } & Şebeke & 0.101 \\
\hline & Şişelenmiş & 0 \\
\hline \multirow{2}{*}{ Çifteler } & Artezyen kuyu & 1441 \\
\hline & Şişelenmiş & 0 \\
\hline \multirow{2}{*}{ Günyüzü } & Şebeke & 0.017 \\
\hline & Şişelenmiş & 0 \\
\hline \multirow{2}{*}{ Han } & Artezyen kuyu & 0.511 \\
\hline & Şişelenmiş & 0 \\
\hline \multirow{2}{*}{ İnönü } & Şebeke & 0 \\
\hline & Şişelenmiş & 0 \\
\hline \multirow{2}{*}{ Mahmudiye } & Şebeke & 0.271 \\
\hline & Şişelenmiş & 0 \\
\hline \multirow{2}{*}{ Mihalgazi } & Şebeke & 0.113 \\
\hline & Şişelenmiş & 0 \\
\hline \multirow{2}{*}{ Mihalıççık } & Şebeke & 0 \\
\hline & Şişelenmiş & 0 \\
\hline \multirow{2}{*}{ Odunpazarı } & Şebeke & 0.095 \\
\hline & Şişelenmiş & 0 \\
\hline \multirow{3}{*}{ Sarıcakaya } & Şebeke & 0 \\
\hline & Artezyen kuyu & 0 \\
\hline & Şişelenmiş & 0 \\
\hline \multirow{2}{*}{ Seyitgazi } & Şebeke & 0.405 \\
\hline & Şişelenmiş & 0 \\
\hline \multirow{2}{*}{ Sivrihisar } & Şebeke & \\
\hline & Şişelenmiş & 0 \\
\hline \multirow{2}{*}{ Tepebaşı } & Şebeke & 0.095 \\
\hline & Şişelenmiş & 0 \\
\hline
\end{tabular}

\section{TARTIŞMA}

Dental florozis, sağlıklı bireyler için önerilen optimum miktarın üzerindeki florürün dişlerin gelişim dönemi sırasında alınımına bağlı olarak oluşan minenin yapısal bozukluğudur.,6-9-12 Son yıllarda diş çürüğünü önleme yöntemlerinde florür kullanımının yaygınlaşmasına bağlı olarak dental florozis prevalansında artış görüldüğü bildirilmektedir. ${ }^{3-8}$ Eskişehir ilinde dental florozis görülme sıklığı ile ilgili çok eski yıllara ait sınır düzeyde veri bulunmaktadır. ${ }^{46}$ Eskişehir 
Osmangazi Üniversitesi Diş Hekimliği Fakültesi Çocuk Diş Hekimliği Anabilim Dalı'na başvuran hastalarda (özellikle Çifteler ilçesinden gelen hastalarda) dental florozise rastlanılmıştır. Ayrıca çocuklarda diş çürüğü ve dental florozis arasındaki ilişkiyi değerlendiren çalışmalar incelendiğinde, farklı ülkelere ait çalışmalar olmasına rağmen $4,7,8,19,33-42$ ülkemizde sınırlı sayıda çalışma bulunduğu görülmektedir. ${ }^{32,43} \mathrm{Bu}$ nedenle araştırmamızda, Eskişehir ilindeki çocuklarda dental florozis görülme sıklığının ve etiyolojik faktörlerinin değerlendirmeyi, dental florozis görülme sıklığının diş çürüğü ile ilişkisinin belirlenmesi amaçlandı.

Geçmişten günümüze kadar dental florozisi teşhis etmek için Dean'in Dental Florozis İndeksi, Thylstrup-Fejerskov İndeksi, Florozisin Diş Yüzey İndeksi, Florozis Risk İndeksi, Kronolojik Florozis Değerlendirme İndeksi, Süt Dişlenmede Dental Florozis İndeksi gibi birçok indeks kullanıldığı görülmektedir. ${ }^{45,47-54}$ Araştırmamızda florozis formlarının ayırt edilmesinde daha detaylı ve hassas olması, tekrar edilebilir olması ${ }^{48,50,55,56}$ nedeniyle dental florozisin şiddetini belirlemek için TFI kullanıldı.

Günümüze kadar yapılan çalışmalarda sudaki florür iyonunun analizi için iyon seçici elektrot ${ }^{57,58}$ ve iyon kromatografi yöntemleri kullanılmıştır. ${ }^{57,59-62}$ İyon kromatografi cihazının yeterli hız, hassasiyet, kolay kullanım, güvenilir klinik veriler sağlaması ve küçük miktarlardaki örneklerin bile analizini sağlaması nedeniyle ${ }^{63,64}$ araştırmamızda kullanılan içme sularındaki florür iyonunun analizi için iyon kromatografi yöntemi tercih edildi.

Diş çürüğü prevalansı gelişmiş ülkelerde son yıllarda düşüş göstermesine rağmen gelişmekte olan ve gelişmemiş ülkelerde hala yaygın olarak görülen çocukluk çağı hastalığıdır. ${ }^{5}$ Köksal ve ark. ${ }^{65}$ Türkiye"de 59 yaş arası çocuklarda yaptıkları çalışmada DMFT'nin 0.27 olduğunu ve kızların erkeklere göre istatistiksel olarak daha yüksek DMFT değerine sahip olduğunu göstermişlerdir. Yılmaz ve ark. ${ }^{66} 1997$ yllında 6-12 yaş arası 2122 öğrenci üzerinde yaptıkları çalışmada ise Erzurum ve Düzce'de DMFT değerinin 1.9 olduğunu saptamışlardır. 6-11 yaş grubu çocuklarda çürük prevalansının değerlendirildiği diğer çalışmalarda ise DMFT değeri Adana'da 0.56 $6^{67}$, Ankara'da ise 1.06 olarak rapor edilmiştir. ${ }^{68}$ i̇stanbul'un Büyükçekmece ilçesindeki 7-12 yaş arasındaki ilkokul çocuklarında yapılan araştırmada DMFT'nin 1.15 olduğu ve kızlar ile erkekler arasında fark olmadığı bildirilmiştir. ${ }^{69}$ Güler ve ark.'nın ${ }^{70}$ yaptığı çalışmada da Malatya'da 7-12 yaş arası çocuklarda DMFT değeri 1.39 olarak tespit edilmiştir. Ayrıca cinsiyetler arasında istatistiksel olarak anlamlı bir farklılık olmadığı da belirtilmiştir. Ülkemizde çocukların ağız-diş sağlığı profilini belirlemek için yapılan geniş çaplı bir çalışmada, 12 yaş grubu çocuklarda DMFT'nin 1.9 olduğu rapor edilmiştir. ${ }^{71}$ Kambek Taşveren ve ark. ${ }^{72}$ Sivas il merkezinde 12 yaş grubu çocuklarda ortalama
DMFT değerini 3.58, Bodur ve ark. ${ }^{73}$ ise Ankara' da 11 12 yaş grubunda DMFS değerini 4.49 olarak bildirmişlerdir. Her iki çalışmada da kız ve erkekler arasında istatistiksel olarak anlamlı bir fark olmadığı gösterilmiştir. Araştırmamızda ise 8-12 yaş çocukların ortalama DMFT değerinin $2.18 \pm 2.00$ olduğu ve kız ve erkek çocukların DMFT ortalamasının ise benzer olduğu gözlendi.

Mann ve ark. ${ }^{74}$ İsrail'de içme suyunda $5 \mathrm{ppm}$ florür bulunan bölgede yaşayan 15-16 yaşındaki 182 adolesan üzerinde yaptıkları inceleme sonucunda tüm çocuklarda dental florozis gözlemlediklerini bildirmişlerdir. Cochran ve ark. ${ }^{75}$ Avrupa'da farklı şehirlerde yaptığı çalışmada 8 yaşındaki çocuklarda TFl'ya göre dental florozis prevalansını İrlanda'da \% 89, İngiltere'de \% 66, Finlandiya'da \% 82, Yunanistan'da \% 53, İzlanda'da \% 68, Hollanda'da \% 80, Portekiz'de \% 51 bulmuşlardır. Meksika'da yapılan çalışmalarda ise dental florozis görülme sıklığı 8-10 yaşında \% 92 ${ }^{12}, 10-12$ yaşında $\% 58.6^{76}$ ve $12-15$ yaşında \% 83.8 olarak tespit edilmiştir. ${ }^{77}$ Antonijevic ve ark. ${ }^{78}$ sudaki florür seviyesi geniş bir aralıkta olan (0.11-4.14 mg/L) yerlerde yaşayan 7-15 yaş arasındaki çocukların \% 34.6'sında dental florozis olduğunu saptamışlardır. 8-12 yaş arası yapılan çocuklarda dental florozis prevalansı Avustralya'da yaklaşık \% 25 (üst çene santral kesici dişlerde) ${ }^{42}$, Brezilya'da \% 8.53 $3^{79}$, Meksika'da \% $46.9^{80}$ ve \% $72.3^{81}$ olarak bildirilmiştir. Brezilya'da 12 yaşındaki çocuklarda dental florozis görülme sıklığı 2010 yılında $\% 18.7^{82}$ iken 2015 yilında \%58.9 ${ }^{83}$ olarak tespit edilmiştir. Literatürde dental florozis görülme sıklığı ile ilgili çalışmalar değerlendirildiğinde farklı yaş gruplarında (5-15 yaş arası) ve farklı ülkelerde yapılan çalışmalarda, dental florozis görülme sıklığının \% 1.776.8 arasında değiştiği gözlenmektedir. ${ }^{37,41,84-91}$ Ülkemizde yapılan çalışmalar incelendiğinde ise, Usmen'in ${ }^{26} 1976$ yılında Isparta ilinde yaptığı çalışmada 5-9 yaş arası çocuklarda dental florozis görülme sıklığı \% 87, 10-14 yaş arası çocuklarda ise $\% 80$ olarak bildirilmiştir. Ermiş ve ark. ${ }^{43} 12-14$ yaş çocuklarda dental florozis prevalansını düşük florürlenmiş bölgede yaşayanlarda $\% 23$, yüksek florürlenmiş bölgede yaşanlarda ise \% 77 olarak rapor etmişlerdir. 2007 yılında Gökalp ve ark. ${ }^{71}$ tarafından Türkiye'de 68 ildeki 4657 çocuğun ağız-diş sağlığı profilini belirlemek için yapılan çalışmada, dental florozis prevalansı 5 yaşta $\% 0.7,12$ yaşta $\%$ 2.6, 15 yaşta \% 3 olarak saptanmış ve dental florozis prevalansının Türkiye'de çok düşük olduğu bildirilmiştir. Çelik ve ark. ${ }^{32}$ Isparta il merkezinde 1112 yaş çocuklarda dental florozis görülme oranının \% 46 olduğunu göstermişlerdir. Eskişehir'de dental florozis ile ilgili ilk çalışma olan Aksit ve ark.'nın ${ }^{46}$ çalışmasında, Beylikova-Kızılcaören köyünde kullanılan kaynakları farklı üç çeşme suyunda yüksek 
oranda florür olduğu (3.8-4.2 ve 4.9 ppm) ve köyde doğup büyüyen 7-14 yaş çocukların hepsinde dental florozis olduğu tespit edilmiştir. Daha sonraki yıllarda sağlıklı su getirildiği öğrenilen bölgedeki olası değişiklikleri değerlendirmek için Oruç ve Akşit 1989 yılında yaptıkları incelemede, suda 0.1-0.25 mg arasında florür bulunduğunu ve ilkokul çağındaki 24 öğrencinin 10 tanesinde dental florozis gözlemlediklerini bildirmişlerdir. Yaptıkları inceleme sonucunda sağlıklı suyun debisinin düşük olması nedeniyle eski çeşmelerin kullanıldığı ve buna bağlı florür toksisitesinin devam ettiğini tespit etmişlerdir. Bizim araştırmamızda ise artık Beylikova bölgesinde florür konsantrasyonu $0.101 \mathrm{ppm}$ olan şebeke suyunun kullanıldığı tespit edilmiş olup dental florozis bulgusuna rastlanılmamıştır. Araştırma sonuçlarımıza göre ise Eskişehir ilinde 8-12 yaş çocuklarda dental florozis görülme sıklığının \% 1.9 olduğu saptandı. Bununla birlikte ilçeler arasında, sudaki florür konsantrasyonunun optimum dozun üzerinde olan Çifteler ilçesinde (1.441 ppm) dental florozis görülme oranının (\%15.2) en yüksek olduğu gözlendi.

Çocuklarda dental florozis görülme sıklığı ile cinsiyet arasında anlamlı bir ilişki olduğu gösteren çalışmalar ${ }^{87,93,94}$ olduğu gibi herhangi bir ilişki olmadığını söyleyen araştırmalarda ${ }^{41,76-79,81,82,91}$ mevcuttur. Bardal ve ark. ${ }^{93}$ ve Rigo ve ark. ${ }^{94}$ ile uyumlu olarak araştırmamızda da kızlarda dental florozis görülme sıklı̆ının erkeklerden istatistiksel olarak daha fazla olduğu tespit edildi.

Dental florozis gözlenen ve gözlenmeyen çocuklarda diş çürüğü görülme sıklığının benzer olduğu, dental florozis ile diş çürüğü görülme sıklığı arasındaki ilişkili değerlendirildiğinde ise diğer çalışmalarla uyumlu olarak 17,38,42,85,86,91,95,96 negatif bir korelasyon olduğu saptandı $(p<0.001)$.Dental florozis ile diş çürüğü görülmesi arasındaki ilişki değerlendirildiğinde, dental florozis gözlenen ve gözlenmeyen çocuklarda diş çürüğü görülme sıklı̆ının benzer olduğu, bununla birlikte diğer çalışmalarla uyumlu olarak ${ }^{17,38,42,85,86,91,95,96}$ dental florozis görülmesi ile çürük arasında negatif bir korelasyon olduğu saptandı.

Çocuklarda dental florozis görülme sıklığı ile dental florozise neden olabilecek etiyolojik faktörler arasındaki ilişkiyi değerlendiren çalışmalar incelendiğinde sonuçların tutarsız olduğu gözlenmiştir. Hindistan'da yapılan çalışmalarda ${ }^{89,90}$ dental florozisin beslenme alışkanlıkları, oral hijyene yardımcı ürünler, diş fırçalama sıklığı ve şeker tüketim sıklığı ile herhangi bir ilişkisi bulunamamıştır. Buna karşın Machiulskiene ve ark. $^{86}$ florürlü diş macunlarının, maruz kalınan florür miktarını arttığı ve bu yüzden dental florozis riskini arttırdığını bildirmişlerdir. Cochran ve ark. ${ }^{75}$ dental florozis ile florürlenmiş su tüketimi ve 2 yaşından sonra florürlü tablet kullanımı arasında ilişki olduğunu göstermişlerdir. Wong ve ark. ${ }^{97}$ yaptıkları meta analiz sonucunda dental florozis ile diş fırçalama sıklığı arasında herhangi bir ilişki olmadığını bildirmesine karşın, Molina-Frechero ve ark. ${ }^{76}$ ve Azevedo ve ark. ${ }^{79}$ yaptıkları çalışmalarında diş fırçalama sıklığı arttıkça dental florozis görülme oranının artıığını tespit etmişlerdir. Do ve ark. ${ }^{23}$ florürlenmiş bölgelerde bebek maması ile dental florozis görülmesi arasında ilişki bulunduğunu saptamışlardır. Azevedo ve ark. ${ }^{79}$ ise anne sütü ile beslenen çocuklarda dental florozis riskinin azaldığını belirtmişlerdir. Araştırmamız sonuçlarına göre de anne sütü ile beslenme süresi ve dental florozis görülme sıklığı arasında anlamlı bir ilişki olduğu ve anne sütü ile uzun süre beslenenlerde dental florozis görülme oranının azaldığı saptandı. Bu bulgu anne sütünün çok düşük florür içeriğine sahip olması ve sadece anne sütü ile beslenenlerin florürlü suya maruz kalmaması ile açıklanabilir. ${ }^{79}$ Ayrıca araştırmamızda anne/babanın eğitim düzeyi, doğumdan itibaren aynı bölgede yaşaması, içme suyunun tipi, okulda kullanılan suyun tipi, macun tipi ile çocukta dental florozis görülme sıklığı arasında istatistiksel olarak anlamlı bir ilişki olduğu saptandı.

İçme sularına florür eklenmesi, ekonomik ve etkin çürük proflaksi yöntemlerinden biridir. ${ }^{98,99}$ Florür takviyesi olarak sadece içme sularının kullanıldığı yıllarda diş çürüğü prevalansında azalma gözlenirken, florür takviyelerinin yaygınlaşması ile birlikte dental florizis görülme oranında ise artı̧ olduğu tespit edilmiştir. $3,4,5,7,8,98 \mathrm{Bu}$ nedenle günümüzde, diş çürüğünü önleme ve dental florozis riski arasındaki denge göz önüne alındığında Amerikan Çocuk Diş Hekimliği Akademisi içme sularına 0.7-1.2 ppm florür katılmasını önermektedir. ${ }^{100}$ Sudaki florür oranı arttıkça dental florozis görülme sıklığının arttığı ve içme suyu florür konsantrasyonu $1.5 \mathrm{mg} / \mathrm{L}$ ve üzerinde olan bölgelerde dental florozis riskinin 4 kat arttığı rapor edilmiştir. ${ }^{101}$ Ruan ve ark. ${ }^{38}$ içme suyundaki florür konsantrasyonu ile dental florozis görülme sıklığı arasında pozitif bir ilişki olduğunu bildirmişlerdir. Ayrıca florür oranı $0.5 \mathrm{ppm}$ altında su tüketenlerde florozisin düşük şiddette olduğunu, ancak 0.8-1.4 ppm su tüketenlerde ise florozisin görülme sıklığının ve şiddetinin arttığını göstermişlerdir. Benzer şekilde Tsutsui ve ark. ${ }^{85}$, Shekar ve ark. ${ }^{41}$, Irigoyen-Camacho ve ark. ${ }^{81}$ ve Pontigo-Loyola ve ark. ${ }^{77}$ da içme suyundaki florür konsantrasyonu ile dental florozis görülme sıklığı arasında direkt bir ilişki olduğunu bulmuşlardır. Ayrıca birçok çalışmada içme suyundaki florür konsantrasyonu arttıkça dental florozisin şiddetinin de arttığı bildirilmiştir. ${ }^{41,77,78}$ Araştırmamızda Eskişehir ilinde kullanılan içme sularının florür konsantrasyonunun 0-1.441 ppm arasında değiştiği gözlendi. Ayrıca diğer çalışmalarla uyumlu olarak ${ }^{38,41,77,78,81,85,101}$ kullanılan içme sularının florür konsantrasyonu ile dental florozis görülme sıklı̆ı ıe şiddeti arasında ilişki olduğu belirlendi. 


\section{SONUÇ}

Araştırmadan elde ettiğimiz bulgular ışığında;

1. Araștırmamıza katılan tüm çocukların ortalama DMFT değerinin $2.18 \pm 2.00$ oldugu ve cinsiyetler arasında anlamlı bir fark olmadığ $(p>0.05)$ belirlendi.

2. Eskişehir ilinde dental florozis gö̈ulme sıklıgının $\% 1.9$ oldugu ve kızlarda dental florozis görulme sıklığnın (\%2.4) erkeklerden (\%1.4) istatistiksel olarak daha fazla oldugu saptandı $(p=0.11)$.

3. Dental florozis varlığ ile dis, çürügü arasında negatif korelasyon oldugu saptandı $(p<0.001)$.

4. Dental florozis görülmesinde içme suyundaki florür konsantrasyonunun yanı sıra anne sütü ile beslenme süresi ve kullanılan macun tipi (flor içermesi) gibi diğer faktörlerin de rol oynadığı belirlendi.

5. Dental florozisin etiyolojisinde rol oynayan faktörlerin bilinmesi ve bu konuda toplumun bilinçlendirilmesinin ve dental florozisin önlenmesinde önemli olduğu görüşündeyiz. 


\section{KAYNAKLAR}

1. Pinkham JR. The Practical Importance of Pediatric Dentistry. Pinkham JR, editor. Pediatric Dentistry Infancy Through Adolescence. 2nd ed. W.B. Saunders Company; 1994. p.2-11.

2. Adair SM. Evidence-based use of fluoride in contemporary pediatric dental practice. Pediatr Dent 2006; 28: 133-42; discussion 92-8.

3. Aoba T, Fejerskov O. Dental fluorosis: chemistry and biology. Crit Rev Oral Biol Med 2002; 13: 155-70.

4. Whelton H, Crowley E, O'Mullane D, Donaldson M, Kelleher V, Cronin M. Dental caries and enamel fluorosis among the fluoridated and non-fluoridated populations in the Republic of Ireland in 2002. Community Dent Health 2004; 21: 37-44.

5. Selwitz RH, Ismail Al, Pitts NB. Dental caries. Lancet 2007; 369: 51-9.

6. Abanto Alvarez J, Rezende KM, Marocho SM, Alves FB, Celiberti P, Ciamponi AL. Dental fluorosis: exposure, prevention and management. Med Oral Patol Oral Cir Bucal 2009; 14: E103-7.

7. Anuradha B, Laxmi GS, Sudhakar $P$, Malik V, Reddy $\mathrm{KA}$, Reddy SN, et al. Prevalence of dental caries among 13 and 15-year-old school children in an endemic fluorosis area: a cross-sectional study. J Contemp Dent Pract 2011; 12: 447-50.

8. Narwaria YS, Saksena DN. Prevalence of dental fluorosis among primary school children in rural areas of Karera Block, Madhya Pradesh. Indian J Pediatr 2013; 80: 718-20.

9. Larsen MJ, Richards A, Fejerskov O. Development of dental fluorosis according to age at start of fluoride administration. Caries Res 1985; 19: 519-27.

10. Horowitz HS. Indexes for measuring dental fluorosis. J Public Health Dent 1986; 46: 179-83.

11.11. Levy SM. An update on fluorides and fluorosis. J Can Dent Assoc 2003; 69: 286-91.

12. Aguilar-Diaz FC, Irigoyen-Camacho ME, BorgesYanez SA. Oral-health-related quality of life in schoolchildren in an endemic fluorosis area of Mexico. Qual Life Res 2011; 20: 1699-706.

13. Ferreira EF, Vargas AM, Castilho LS, Velasquez LN, Fantinel LM, Abreu MH. Factors associated to endemic dental fluorosis in Brazilian rural communities. Int J Environ Res Public Health 2010; 7: 3115-28.

14. Sharma A. Fluoride and Fluorosis, 1st edn. New Delhi: Jaypee Brothers Medical Publishers, 2014. p.1-98.

15.Grobler SR, van Wyk CW, Kotze D. Relationship between enamel fluoride levels, degree of fluorosis and caries experience in communities with a nearly optimal and a high fluoride level in the drinking water. Caries Res 1986; 20: 284-8.
16. Ekstrand J, Fejerskov O, Silverstone LM. Fluoride in Dentistry, 1st edn. Copenhagen: Munksgaard, 1988. p.13-28, 171-276.

17.Szpunar SM, Burt BA. Dental caries, fluorosis, and fluoride exposure in Michigan schoolchildren. J Dent Res 1988; 67: 802-6.

18.DenBesten PK, Thariani H. Biological mechanisms of fluorosis and level and timing of systemic exposure to fluoride with respect to fluorosis. J Dent Res 1992; 71: 1238-43.

19. Menon A, Indushekar KR. Prevalence of dental caries and co-relation with fluorosis in low and high fluoride areas. J Indian Soc Pedod Prev Dent 1999; 17: 15-20.

20.Şaroğlu I, Aras Ş. Florozis. Ankara Üniv Diş Hekim Fak Derg 2001; 28: 239-50.

21. Hujoel PP, Zina LG, Moimaz SA, Cunha-Cruz J. Infant formula and enamel fluorosis: a systematic review. J Am Dent Assoc 2009; 140: 841-54.

22.Levy SM, Broffitt B, Marshall TA, EichenbergerGilmore JM, Warren JJ. Associations between fluorosis of permanent incisors and fluoride intake from infant formula, other dietary sources and dentifrice during early childhood. J Am Dent Assoc 2010; 141: 1190-201.

23.Do LG, Levy SM, Spencer AJ. Association between infant formula feeding and dental fluorosis and caries in Australian children. $J$ Public Health Dent 2012; 72: 112- 21.

24.Şendil Ç, Bayşu N. İnsan ve hayvanlarda Ağrı ili Dogubeyazıt ilçesi köylerinde görülen flor zehirlenmesi ve bunu Van ili Muradiye ilçesi köylerinde de saptamamıla ilgili ilk teblig. Ankara Üniv Vet Fak Derg 1973; 10: 474-89.

25. Oruç N, Alpman N, Karamanderesi liH . Tendürek volkanı çevresindeki yüksek fluorür içerikli kaynak sularının hidrojelojisi. Türkiye Jeoloji Kurumu Bülteni 1976; 19: 1-8.

26. Usmen E. Isparta il, ilçe ve köylerinde diş fluorosisi. İstanbul Üniv Diş Hekim Fak Derg 1976; 10: 285-96.

27.Fidanci UR, Salmanoğlu B, Maraşli S, Maraşli N. İ, Anadolu bolgesinde doğal ve endüstriyel florozis ve bunun hayvan sağlığı üzerindeki etkileri. Turk J Vet Anim Sci 1998; 22: 537-44.

28. Altıntaş A, Fidancı UR, Sel T, Duru Ö, Başsatan A. Doğal ve endüstriyel florozisli koyunlarda böbrek fonksiyonu ve serum protein elektroforezi. Ankara Üniv Vet Fak Derg 2000; 47: 105-14.

29. Fidanci UR, Sel T. The industrial fluorosis caused by a coal-burning powerstation and its effects on sheep. Turk J Vet Anim Sci 2001; 25: 735-41. 
30.Savas S, Cetin M, Akdogan M, Heybeli N. Endemic fluorosis in Turkish patients: relationship with knee osteoarthritis. Rheumatol Int 2001; 21 : 30-5.

31. Oruc N. Occurrence and problems of high fluoride waters in Turkey: an overview. Environ Geochem Health 2008; 30: 315-23.

32. Çelik EU, Çelik B, Önal S, Örmeci A, Ulutaş $H$. Isparta ilindeki 11-12 yaşındaki çocukların diş çürüğü ve florozis prevalansının değerlendirilmesi. Atatürk Üniv Diş Hekim Fak Derg 2010; 20: 170-5.

33. Jackson RD, Kelly SA, Katz BP, Hull JR, Stookey GK. Dental fluorosis and caries prevalence in children residing in communities with different levels of fluoride in the water. J Public Health Dent 1995; 55: 79-84.

34. Ibrahim YE, Bjorvatn K, Birkeland JM. Caries and dental fluorosis in a 0.25 and a 2.5 ppm fluoride area in the Sudan. Int J Paediatr Dent 1997; 7: 161-6.

35.Stephen KW, Macpherson LM, Gilmour WH, Stuart RA, Merrett MC. A blind caries and fluorosis prevalence study of school-children in naturally fluoridated and nonfluoridated townships of Morayshire, Scotland. Community Dent Oral Epidemiol 2002; 30: 70-9.

36. Ekanayake L, van der Hoek W. Prevalence and distribution of enamel defects and dental caries in a region with different concentrations of fluoride in drinking water in Sri Lanka. Int Dent J 2003; 53: 243-8.

37. Wondwossen F, Astrom AN, Bjorvatn K, Bardsen A. The relationship between dental caries and dental fluorosis in areas with moderate- and highfluoride drinking water in Ethiopia. Community Dent Oral Epidemiol 2004; 32: 337-44.

38. Ruan JP, Yang ZQ, Wang ZL, Astrom AN, Bardsen A, Bjorvatn K. Dental fluorosis and dental caries in permanent teeth: rural schoolchildren in highfluoride areas in the Shaanxi province, China. Acta Odontol Scand 2005; 63: 258-65.

39. Narbutaité J, Vehkalahti MM, Milciuviené S. Dental fluorosis and dental caries among 12-yr-old children from high- and low-fluoride areas in Lithuania. Eur J Oral Sci 2007; 115: 137-42.

40.AIDosari AM, Akpata ES, Khan N. Associations among dental caries experience, fluorosis, and fluoride exposure from drinking water sources in Saudi Arabia. J Public Health Dent 2010; 70: 2206.

41. Shekar C, Cheluvaiah MB, Namile D. Prevalence of dental caries and dental fluorosis among 12 and 15 years old school children in relation to fluoride concentration in drinking water in an endemic fluoride belt of Andhra Pradesh. Indian $J$ Public Health 2012; 56: 122-8.
42.Do LG, Miller J, Phelan C, Sivaneswaran S, Spencer AJ, Wright C. Dental caries and fluorosis experience of 8-12-year-old children by early-life exposure to fluoride. Community Dent Oral Epidemiol 2014; 42: 553-62.

43. Ermis RB, Koray F, Akdeniz BG. Dental caries and fluorosis in low- and high fluoride areas in Turkey. Quintessence Int 2003; 34: 354-60.

44.World Health Organization, Oral Health Surveys Basic Methods. 5th edn. Geneva: World Health Organization Publications, 2013. p.13-125.

45. Thylstrup A, Fejerskov O. Clinical appearance of dental fluorosis in permanent teeth in relation to histologic changes. Community Dent Oral Epidemiol 1978; 6: 315-28.

46. Aksit MA, Tel E, Bilir S. Kızılcaören-a health survey in an endemic fluorosis village. Fluoride 1980; 13: 81-5.

47. Dean HT. Classification of mottled enamel diagnosis. J Am Dent Assoc 1934; 21: 1421-6.

48. Pendrys DG. The fluorosis risk index: a method for investigating risk factors. J Public Health Dent 1990; 50: 291-8.

49.Burger $\mathrm{P}$, Cleaton-Jones $\mathrm{P}$, du Plessis J, de Vries J. Comparison of two fluorosis indices in the primary dentition of Tswana children. Community Dent Oral Epidemiol 1987; 15: 95-7.

50.Rozier RG. Epidemiologic indices for measuring the clinical manifestations of dental fluorosis: overview and critique. Adv Dent Res 1994; 8: 39-55.

51. Horowitz HS, Driscoll WS, Meyers RJ, Heifetz SB, Kingman A. A new method for assessing the prevalence of dental fluorosis--the Tooth Surface Index of Fluorosis. J Am Dent Assoc 1984; 109: 37-41.

52. Pereira AC, Moreira BH. Analysis of three dental fluorosis indexes used in epidemiologic trials. Braz Dent J 1999; 10: 29-37.

53.Evans RW. An epidemiological assessment of the chronological distribution of dental fluorosis in human maxillary central incisors. J Dent Res 1993; 72: 883-90.

54.Layola-Rodriguez JP, Pozos-Guillen AJ, HernandezGuerrero JC, Hernandez-Sierra JE. Fluorosis in primary dentition in a region with endemic water fluoride. Salud Publica Mex 2000; 42: 194-200.

55. Funmilayo AM, Mojirade AD. Dental Fluorosis and its Indices, what"s new? IOSR-JDMS 2014; 13: 55-60.

56. Granath L, Widenheim J, Birkhed D. Diagnosis of mild enamel fluorosis in permanent maxillary incisors using two scoring systems. Community Dent Oral Epidemiol 1985; 13: 273-6.

57. Demer SA, Memiş Ü. Isparta il merkezinde içme sularının farklı florür içeriklerinin incelenmesi. Ekoloji 2011; 20: 77-82.

58. Işıklı B, Kalyoncu C, Metintaş S, Demir TA. Eskişehir yöresindeki içme sularında florür düzeyleri. Ekoloji 2009; 9: 28-30. 
59.Brahman KD, Kazi TG, Afridi HI, Naseem S, Arain SS, Ullah N. Evaluation of high levels of fluoride, arsenic species and other physicochemical parameters in underground water of two sub districts of Tharparkar, Pakistan: a multivariate study. Water Res 2013; 47: 1005-20.

60. Cochrane NJ, Hopcraft MS, Tong AC, Thean H, Thum YS, Tong DE, et al. Fluoride content of tank water in Australia. Aust Dent J 2014; 59: 180-6.

61. Maraver F, Vitoria I, Almerich-Silla JM, Armijo F. Fluoride content of bottled natural mineral waters in Spain and prevention of dental caries. Aten Primaria 2015; 47: 15-24.

62. Ley $P$, Sturm M, Ternes TA, Meermann B. Highresolution continuum source graphite furnace molecular absorption spectrometry compared with ion chromatography for quantitative determination of dissolved fluoride in river water samples. Anal Bioanal Chem 2017; 409:6949-58.

63. Singh RP, Smesko SA, Abbas NM. Ion chromatographic characterization of toxic solutions: analysis and ion chemistry of biological liquids. J Chromatogr A 1997; 774: 21-35.

64. Itota T, Carrick TE, Rusby S, Al-Naimi OT, Yoshiyama $\mathrm{M}, \mathrm{McCabe}$ JF. Determination of fluoride ions released from resin-based dental materials using ionselective electrode and ion chromatograph. J Dent 2004; 32: 117-22.

65. Koksal E, Tekcicek M, Yalcin SS, Tugrul B, Yalcin S, Pekcan G. Association between anthropometric measurements and dental caries in Turkish school children. Cent Eur J Public Health 2011; 19: 147-51.

66. Yılmaz AB, Orbak R, Çanakçı N, Nişli ON, Eminoğlu A. Erzurum ve Düzce'de 6-12 yaş grubu bireylerde CPITN, df, dmf indekslerini kullanarak periodontal hastalıklar ile diş çürüğünün değerlendirilmesi ve iki bölgenin karşılaştırılması. Atatürk Üniv Diş Hekim Fak Derg 1997; 7: 5-11.

67.Öztunç H, Haytaç MC, Özmeriç N, Uzel İ. Adana ilinde 6-11 yaş grubu çocukların ağız-diş sağlığı durumlarının değerlendirilmesi (Adana DSi illköğretim Okulu, 1999). Gazi Üniv Diş Hek Fak Derg 2000; 17: 1-6.

68. Altun C, Güven G, Başak F, Akbulut E. Altı-onbir yaş grubu çocukların ağız-diş sağlığı yönünden değerlendirilmesi. Gülhane Med J 2005; 47: 114-8.

69.Akıncı T, Aktören O, Sepet E, Oray H, Sağlam E, Burmabıyıkoğlu S, et al. İstanbul Büyükçekmece ilçesi ilkokul çocuklarında diş çürüğü sıklığı. İstanbul Üniv Diş Hekim Fak Derg 1998; 32: 16-21.

70.Güler Ç, Eltaş E, Güneş D, Görgen VA, Ersöz M. Malatya ilindeki 7-14 yaş arası çocukların ağız-diş sağlığının değerlendirilmesi. İnönü Üniv Sağlık Bilim Derg 2012; 1: 19-24.

71. Gökalp S, Güçiz Doğan B, Tekçiçek M, Berberoğlu A, Ünlüer Ş. Beş, on iki ve on beş yaş çocukların ağız diş sağlığı profili, Türkiye-2004. Hacettepe Diş Hek Fak Derg 2007; 31: 3-10.
72. Kambek Taşveren S, Yalçın Yeler D, Sözen A, Taşveren $S .12$ yaş grubu çocukların diş fırçalama sıklığı-dmf-t ilişkisi. Atatürk Üniv Diş Hekim Fak Derg 2005; 15: 11-4.

73. Bodur H, Bodur A, Yücesoy V, Baloş K. İki farklı yaş grubunda diş çürüğü prevelansı ve periodontal durumun değerlendirilmesi. Gazi Üniv Diş Hek Fak Derg 2004; 21: 35-9.

74. Mann J, Tibi M, Sgan-Cohen HD. Fluorosis and caries prevalence in a community drinking aboveoptimal fluoridated water. Community Dent Oral Epidemiol 1987; 15: 293-5.

75. Cochran JA, Ketley CE, Arnadottir IB, Fernandes $B$, Koletsi-Kounari $H$, Oila AM, et al. A comparison of the prevalence of fluorosis in 8-year-old children from seven European study sites using a standardized methodology. Community Dent Oral Epidemiol 2004; 32: 28-33.

76. Molina-Frechero N, Gaona E, Angulo M, Sanchez Perez L, Gonzalez Gonzalez R, Nevarez Rascon $M$, et al. Fluoride exposure effects and dental fluorosis in children in Mexico City. Med Sci Monit 2015; 21: 3664-70.

77.Pontigo-Loyola AP, Islas-Marquez A, LoyolaRodriguez JP, Maupome G, Marquez-Corona ML, Medina-Solis CE. Dental fluorosis in 12- and 15year-olds at high altitudes in above-optimal fluoridated communities in Mexico. J Public Health Dent 2008; 68: 163-6.

78.Antonijevic E, Mandinic Z, Curcic M, Djukic-Cosic $D$, Milicevic N, Ivanovic $M$, et al. "Borderline" fluorotic region in Serbia: correlations among fluoride in drinking water, biomarkers of exposure and dental fluorosis in schoolchildren. Environ Geochem Health 2016; 38: 885-96.

79. Azevedo MS, Goettems ML, Torriani DD, Demarco FF. Factors associated with dental fluorosis in school children in southern Brazil: a crosssectional study. Braz Oral Res 2014; 28: 1-7.

80. Garcia-Perez A, Irigoyen-Camacho ME, BorgesYanez SA, Zepeda-Zepeda MA, Bolona-Gallardo I, Maupome G. Impact of caries and dental fluorosis on oral health related quality of life: a cross-sectional study in schoolchildren receiving water naturally fluoridated at above-optimal levels. Clin Oral Investig 2017; 21: 2771-80.

81.Irigoyen-Camacho ME, Garcia Perez A, Mejia Gonzalez A, Huizar Alvarez R. Nutritional status and dental fluorosis among schoolchildren in communities with different drinking water fluoride concentrations in a central region in Mexico. Sci Total Environ 2016; 541: 512-9.

82. Jordão LM, Vasconcelos DN, Moreira Rda S, Freire Mdo C. Dental fluorosis: prevalence and associated factors in 12-year-old schoolchildren in Goiânia, Goiás. Rev Bras Epidemiol 2015; 18 : 568-77. 
83. Moimaz SA, Saliba O, Marques LB, Garbin CA, Saliba NA. Dental fluorosis and its influence on children's life. Braz Oral Res 2015; 29:1-7.

84. Costa Sde M, Abreu MH, Vargas AM, Vasconcelos M, Ferreira e Ferreira E, Castilho LS. Dental caries and endemic dental fluorosis in rural communities, Minas Gerais, Brazil. Rev Bras Epidemiol 2013; 16: 1021-8.

85. Tsutsui A, Yagi M, Horowitz AM. The prevalence of dental caries and fluorosis in Japanese communities with up to $1.4 \mathrm{ppm}$ of naturally occurring fluoride. J Public Health Dent 2000; 60: 147-53.

86. Machiulskiene V, Baelum V, Fejerskov O, Nyvad B. Prevalence and extent of dental caries, dental fluorosis, and developmental enamel defects in Lithuanian teenage populations with different fluoride exposures. Eur J Oral Sci 2009; 117: 15460.

87. Kotecha PV, Patel SV, Bhalani KD, Shah D, Shah VS, Mehta KG. Prevalence of dental fluorosis \& dental caries in association with high levels of drinking water fluoride content in a district of Gujarat, India. Indian J Med Res 2012; 135: 873-7.

88. McGrady MG, Ellwood RP, Maguire A, Goodwin M, Boothman N, Pretty IA. The association between social deprivation and the prevalence and severity of dental caries and fluorosis in populations with and without water fluoridation. BMC Public Health 2012; 12: 1122.

89. Shanthi M, Reddy BV, Venkataramana V, Gowrisankar S, Reddy BV, Chennupati S. Relationship between drinking water fluoride levels, dental fluorosis, dental caries and associated risk factors in 9-12 years old school children of Nelakondapally Mandal of Khammam District, Andhra Pradesh, India: a cross-sectional survey. J Int Oral Health 2014; 6: 106-10.

90.Sukhabogi Jr, Parthasarathi P, Anjum S, Shekar B, Padma C, Rani A. Dental fluorosis and dental caries prevalence among 12 and 15-year-old school children in Nalgonda District, Andhra Pradesh, India. Ann Med Health Sci Res 2014; 4: S245-52.

91.Narbutaitè J, Virtanen JI, Vehkalahti MM. Variation in fluorosis and caries experience among Lithuanian 12 year olds exposed to more than 1 ppm F in tap water. J Investig Clin Dent 2016; 7: 187-92.

92. Oruç N, Akşit MA. A health survey in a village with endemic fluorisis, 1978-1988. Çevre'89, Çevre Genel Müdürlüğü, Çukurova Üni, Adana 7-9 Haziran 1989.

93. Bardal PA, Olympio KP, Buzalaf MA, Bastos JR. Dental caries and dental fluorosis in 7-12-year-old schoolchildren in Catalao, Goias, Brazil. J Appl Oral Sci 2005; 13: 35-40.
94.Rigo L, Caldas Junior AF, de Souza EH. Factors associated with dental fluorosis. Rev Odonto Ciênc 2010; 25: 8-14.

95. Angelillo IF, Romano F, Fortunato L, Montanaro D. Prevalence of dental caries and enamel defects in children living in areas with different water fluoride concentrations. Community Dent Health 1990; 7: 229-36.

96. Tuli A, Rehani U, Aggrawal A. Caries experience evidenced in children having dental fluorosis. Int J Clin Pediatr Dent 2009; 2: 25-31.

97.Wong MC, Glenny AM, Tsang BW, Lo EC, Worthington HV, Marinho VC. Topical fluoride as a cause of dental fluorosis in children. Cochrane Database Syst Rev 2010; 20;(1): CD007693.

98.Atabey E. Türkiye'de İçme Suyunda Flor ve Etkileri. 1. Baskı. Ankara: Ares Basım Reklam Produksiyon Hizmetleri San Tic Ltd Sți, 2010. p.188.

99. Ergin E, Eden E. Florun insan sağlığına olumsuz etkisi var mı? Ege Üniv Diş Hek Fak Derg 2017; 38: $13-20$.

100. American Academy of Pediatric Dentistry. Guideline on fluoride therapy. Pediatr Dent 2014; 36: 171-4.

101. Indermitte E, Saava A, Karro E. Exposure to high fluoride drinking water and risk of dental fluorosis in Estonia. Int J Environ Res Public Health 2009; 6: 710-21.

Yazışma Adresi:

Doç. Dr. Nuray TÜLOĞLU

Eskişehir Osmangazi Üniversitesi

Diş Hekimliği Fakültesi

Çocuk Diş Hekimliği Anabilim Dalı

Meşelik Kampüsü, Eskişehir, Türkiye

Tel : : +902222393750 / 1485

Faks : +90 2222391273

e-Posta: nuraytuloglu@yahoo.com 